\title{
Microtopia in Counterpoint: Relational Aesthetics and the Echo Project
}

Alexandrine Boudreault-Fournier ${ }^{1}$ University of Victoria, British Columbia, Canada

This article takes as its starting point the ethnographic experience of producing and editing a series of video clips that virtually unite musicians who have never met and who live in different places; it engages with the experience of producing an illusion, a virtual encounter, and a relational piece. The Echo project and its associated installation, "Echo the first tie", were created with the aim of exploring the concept of "microtopias in the present" as developed by Nicolas Bourriaud (2001). In creating "microtopias", or spaces of exchanges and conviviality, the project questions the nature of the anthropologist's involvement in the field as well as her relationship with the people she works with. This article discusses the nature of the relations provoked by an anthropologist during the production of a project that aimed to create a virtual space of encounter. More specifically, in this case, it looks at the meaning of an improvised musical performance in counterpoint. Finally, this article critically examines the Echo project in order to deeply reflect on what could constitute a relational aesthetics-based audio-visual ethnography.

Key words: Relational aesthetics, video, microtopias, montage, music, Cuba

\section{INTRODUCTION}

This article argues that "relational art", a term adopted by writer and curator Nicolas Bourriaud (2001) to refer to artistic practices emerging in the 1990s, offers both challenges and creative opportunities to the discipline of anthropology. The Echo research project and the associated audio-visual installation "Echo $\sim$ the first tie" provide a concrete case study by which to explore these dimensions. The Echo project is an ethnographic initiative that aimed to unite

1 Author's contact email: alexbf@uvic.ca. 
Cuban musicians, two living in Montréal and five in Santiago de Cuba, thanks to video prerecordings, with the goal of creating an original audio-visual piece. This project aimed to create a virtual "cartography of encounter" that merges an anthropological approach with a relational aesthetic. The ultimate goal of the Echo project was to address what should constitute an ethnography of sound and image production.

"Echo the first tie" (2010) consisted of an interaction between Eduardo, a Cuban trumpet player living in Montréal, and Yeniset, a tresera from Santiago de Cuba. Production and montage techniques were deliberately used to suggest visually that the musicians were performing side-by-side, thus creating a "utopian microtopia" (Bourriaud 2001). In reality, these two musicians never physically met; they never talked to each other and never had any form of direct and simultaneous communication. Nevertheless, I argue that this piece is the result of an inter-subjective exchange between two musicians, an exchange that we deliberately provoked through a process that essentially rested on the fact that I and collaborator-filmmaker MarieJosée Proulx physically travelled to Montréal, Santiago de Cuba, and then back to Montréal, which was made possible thanks to digital video and sound recording technologies. "Echo the first tie" was presented at the Eastern Bloc art centre during the Ethnographic Terminalia initiative in Montréal in 2011. Ethnographic Terminalia is a collective exhibition that takes place at the same time as the annual meetings of the American Anthropological Association. It constitutes a "para-site" that aims to provide a "diversity of material, conceptual, and creative engagements with art and anthropology, capturing a multiplicity of mediums where anthropology and art intersect”. ${ }^{2}$

In this article I explore the nature of the relation provoked by the process of producing the Echo project, and of editing the videos that act as virtual relational spaces. I critically examine the challenges of designing and creating a virtual encounter based on video and sound recording and editing as part of my ethnographic fieldwork. The concepts of mise-en-scène and montage are explored to discuss the processes of creating and engaging with "microtopias in the present", and with the imagining of an aesthetic of the relation in anthropology. The experience of producing the Echo project as well as my reflections on its potential to engage with the fieldwork enterprise, allows for the burgeoning of an innovative anthropological aesthetic based on conscious transformations of images and sounds.

\section{IMAGINING ECHO}

The idea behind the Echo project resulted from a series of fortuitous encounters with montage effects and digital illusions. I remember being impressed by a music video featuring Céline Dion and Elvis Presley singing "If I can Dream" side by side for an episode of "American Idol" that was first broadcast in 2009. "The illusion was complete. More than the performance itself, what captivated me most was the use of editing technics to give the impression that they were sharing the same time and space, that they were actually together. Moreover, the performance took place live, in front of an ecstatic audience. I later found out that the illusion of the "impossible duet coming to life" was made possible by a technique called "rotoscoping", which

2 Ethnographic Terminalia website http://ethnographicterminalia.org/.

3 The clip is available on YouTube: https://www.youtube.com/watch?v=c7OFl3TJSUk 
consists of extracting a character from original footage, in addition to several other production and montage techniques. ${ }^{4}$

The techniques used to produce such a "microtopia", or space of inter-subjective encounter, between people who could not physically be together, became a rich source of reflection for me on how I could define an ethnographic encounter. I began to think in terms of producing a space in which I would provoke a relational encounter, following the example of the artists described by Bourriaud in Esthétique relationelle (2001), in order to reflect on the concept of mediation and the nature of relations in the context of ethnographic fieldwork.

The Echo project is about creating a space in which musicians can relate through an improvised musical performance, and in this context sound became one of the most important elements from which an aesthetic of the relation was designed. In Contrapunteo cubano del tabaco y el azúcar (1983), ${ }^{5}$ the famous Cuban anthropologist Fernando Ortiz develops a "contrapuntal" argument to refer to the cultural processes of transculturation that can be observed in Cuba since the colonial era. Ortiz's essay Contrapunteo cubano was translated into English as Cuban Counterpoint, which offers an interesting analogy to music theory. The term counterpoint refers to a technique that consists of combining two or more melodic lines in a harmonic relationship, while retaining the individual linearity of each component. ${ }^{6}$ In developing a playful allegory between sugar and tobacco, as two agricultural products that also correspond to two social features of "the" Cuban, Ortiz emphasizes the various cultural components that create the contemporary cubanidad. He defines cubanidad as the Cuban "way of being, its character, its quality, its distinctive condition, its individuation inside of the universal" (Ortiz 2014). He further uses the example of the Cuban ajiaco, a stew made up of different ingredients including meat, vegetables and roots to illustrate the idea that Cuban culture is united by a common entity (the broth of the stew itself) and identifiable (but cooked) ingredients. The ajiaco is somewhat a utopic dish; it always has a different taste, according to the ingredients used, and its flavour changes through the cooking process (see Palmié 2013 for an in-depth exploration of the metaphor). The ajiaco echoes Cuban culture, perceived by Ortiz as being in a constant process of transculturation. In relation to the Echo project, the musical counterpoint became a fundamental element to define the relation between the two musicians; I will come back to this observation in my concluding remarks.

Another fundamental source of inspiration for the Echo project was the work of media artist, musician and researcher Atau Tanaka, who used the Internet in an attempt to collapse geographical distances (Tanaka 2006). In the 1990s, Tanaka organized a series of concerts connecting Paris and New York, Barcelona and Rotterdam, Budapest and Montréal, and Tokyo and Paris. He played with the "time lags" associated to the time required for data transmission across the Internet (which lasted between 0.5 and 30 seconds-it was in the 1990s) as a source of creation rather than as a form of latency to be eliminated. Tanaka decided to write music for the situation at hand rather than trying to reduce its temporal distances. Referring to his instal-

4 Debates are still ongoing as to which specific techniques were used to produce the performance, with some people mentioning the use of holograms.

5 The book was translated into English as: Cuban Counterpoint, Tobacco and Sugar.

6 In Spanish, contrapunteo refers to an argument, a debate. It comes from the verb contrapuntear. Even if not a perfect translation of contrapunteo, counterpoint brings the idea of duality, complementary and contrast that is associated with the Spanish term. Countrapunteo, as used in Spanish, does not have a musical meaning and it might not have been the intention of Ortiz to create that parallel. 
lations, Tanaka writes that: "Rather than controlling time and space with sound, I seek to create architectures for collective musical processes" (Tanaka 2006:281). Likewise, the production of musical and visual "architectures of encounter", of an infrastructure that would allow a virtual relation to take shape, became the main objective of my fieldwork with the Echo project.

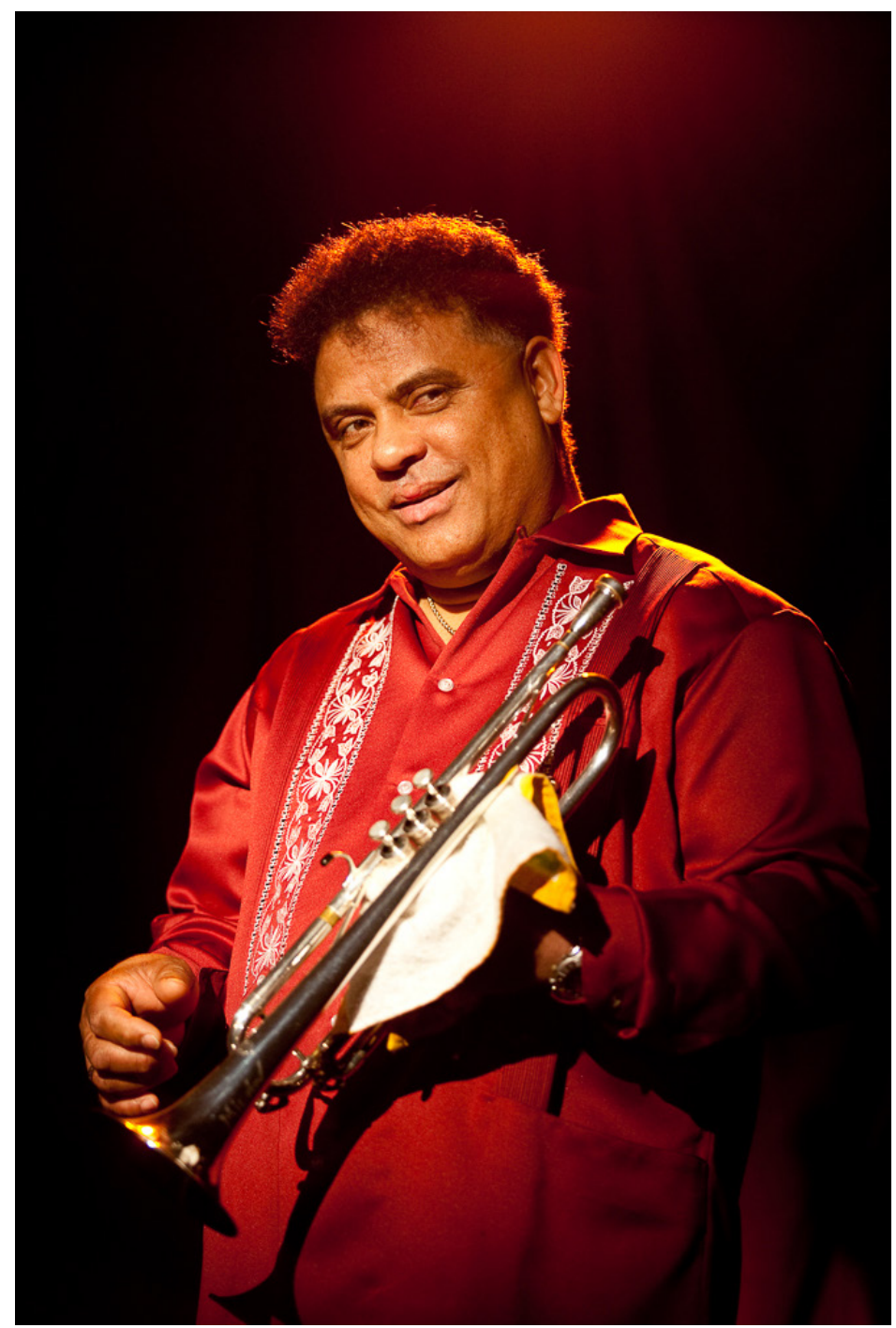

Illustration 1: Eduardo Sánchez. Credit: Simon Couturier.

\section{Producing Echo}

Echo is a video and audio project that involves the mise-en-scène or setting up of an encounter between two musicians who were separated by geographical distances and who could not be connected through the Internet. The project consisted of audio and video recordings by the anthropologist, in collaboration with the filmmaker Marie-Josée Proulx, in two main locations: Montréal and Santiago de Cuba.

The architecture of the encounter that Marie-Josée Proulx and I created during the Echo Project was shaped by technological limitations, mainly the absence of high-speed Internet in 
Cuba, which would have allowed us to re-create the experiment of Tanaka mentioned above. Despite recent changes, Cuba still has one of the world's lowest Internet penetration rates. ${ }^{7}$ At the time of producing the Echo project, Internet access was extremely limited and slow for the majority of the population. Only a few Cubans (artists and university students, among others) had legal access to the Internet. Some Cubans had access to email accounts and national and international networks. Yet, still today, even if the situation is changing rapidly, Internet access remains limited for a large proportion of the population. The level of access is even lower in rural areas and on the eastern end of the island, such as in Santiago de Cuba, where the Cuban phase of the Echo project took place. Because of these technological restrictions, the anthropologist and the filmmaker had to physically provoke the exchange, acting as the network connection between the musicians.

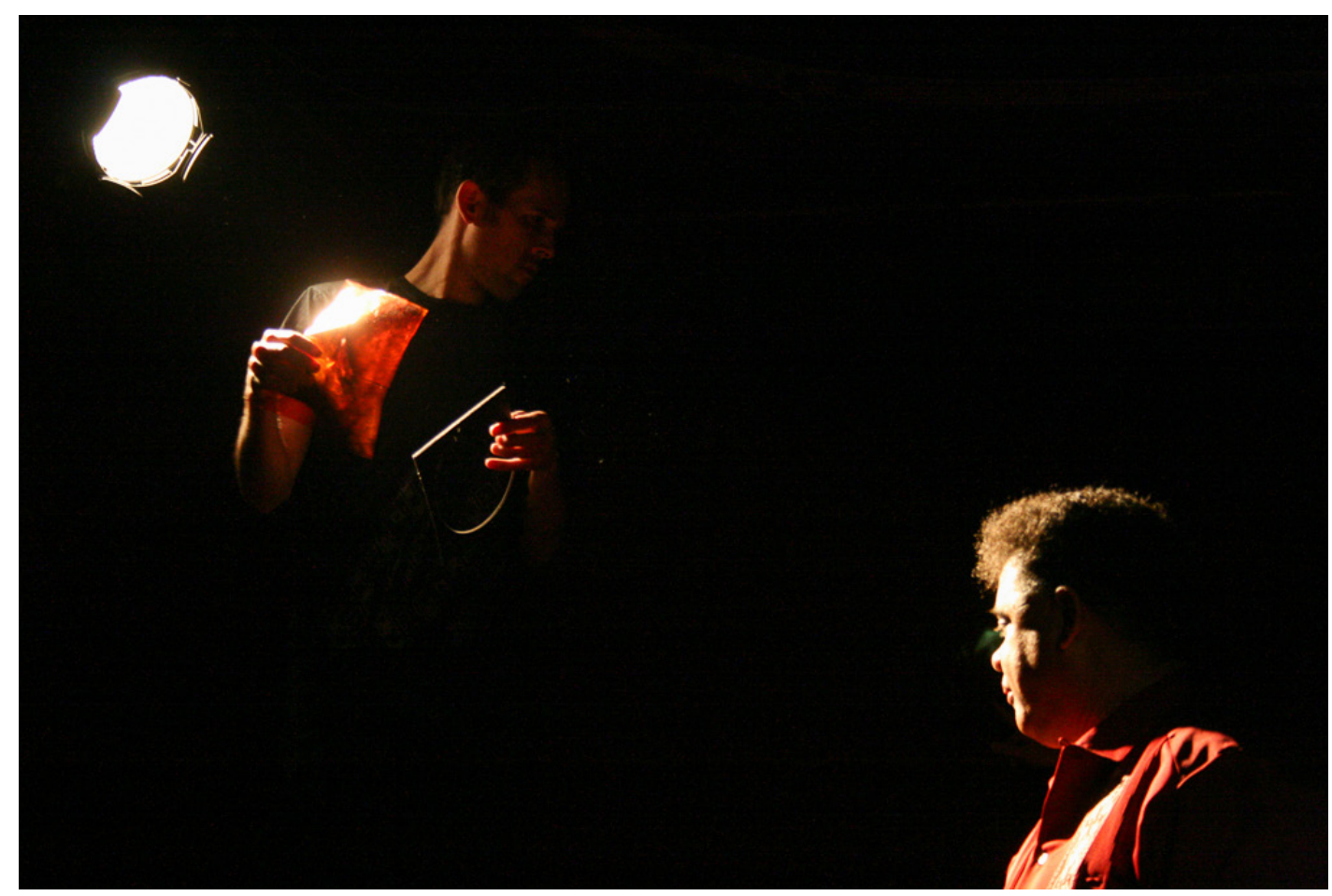

Illustration 2: Creating the Space. Credit: Alexandrine Boudreault-Fournier.

The Echo project was carried out over three main stages, which would all contribute to creating an inter-subjective relation between the musicians (duets) located in different geographical locations. The first stage took place in Montréal, where we met with trumpet player Eduardo Sánchez, who had previously lived in Canada for more than 14 years. Eduardo comes from a family of musicians and learned to play the trumpet as a child. In Cuba, he was a member of the famous group, Son 14, with which he toured many countries around the world. Because of Eduardo's experience and talent for improvisation, we thought he would be an excellent participant in our project. Once we explained the aim of the project to Eduardo, we asked him to improvise by playing songs he liked or that made him think about Cuba. For three hours we recorded Eduardo in a theatre room in Montréal called Sala Rossa. In order to produce the

7 BBC news, May 31, 2013, http://www.bbc.co.uk/news/world-latin-america-22696637 (retrieved June 13, 2013). As for the Caribbean region, according to the most recent data available, only Haiti has a lower Internet penetration rate: $8.5 \%$ in Haiti (2011) compared to 23.2\% in Cuba (2012) (www.internetworldstats.com, retrieved June 13, 2012). Yet, the Cuban rate is biased because it includes the use of Intranet (national internet with no international access) and public Internet stations. 
desired effect, we asked Eduardo to play as if he was playing alongside another musician. More specifically, we asked him to listen and react to what an imaginary musician would play beside him (see illustration 1). The lighting and the sound atmosphere were meticulously planned out and created. In order to facilitate the technical aspects of the project, we decided to use directional lighting, with a hint of red and orange, surrounded by a dark stage. This aesthetic would subsequently have to be reproduced in the later stages of the project; it established the general aesthetics of the "zone" in which the musicians would meet (see illustration 2).

With the rough audio and video material that we collected during the project's first stage, we edited a 1'24" clip during which Eduardo performed a series of excerpts from musical pieces, as well as improvisation. Eduardo was alone on a dark stage, but one can imagine the presence of another musician playing beside him (see video clip 1).

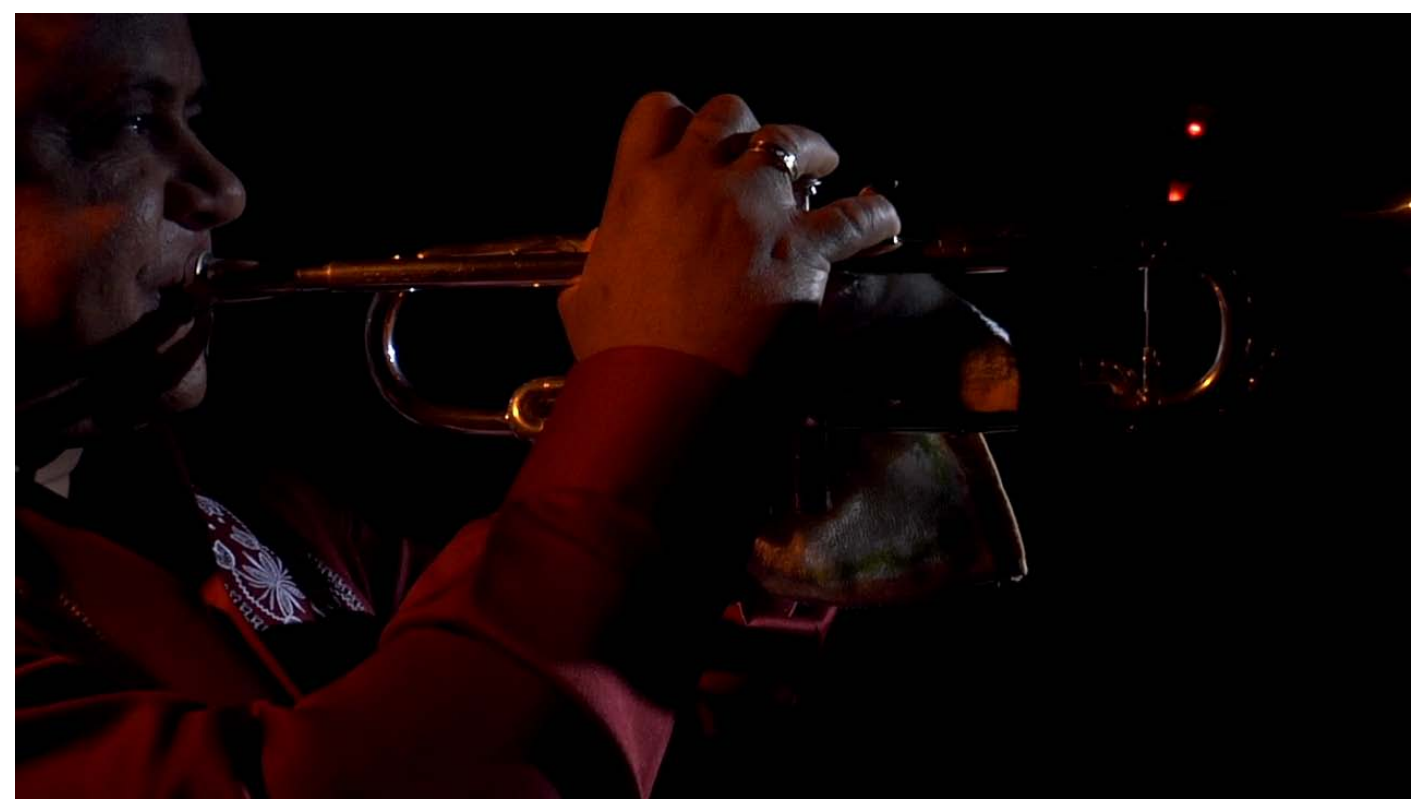

Video 1: Eduardo on a dark stage in Montréal. Credits: Alexandrine Boudreault-Fournier and Marie-Josée Proulx.

The production of the first clip addressed three main objectives. Firstly, we needed to experiment with the video and sound equipment. Secondly, we wanted to create an aesthetic that, from a technological perspective, would enable the inter-subjective encounter to occur. Thirdly, we wanted to produce a tool that would initiate interaction between the musicians, that would trigger their imagination. This clip would not be used in the final stage of the project. It would remain the tool of the relation; it is part of the infrastructure that would frame the "cartography of the encounter".

For the second step of the project, Marie-Josée Proulx and I travelled to Santiago de Cuba. We presented the video clip of Eduardo to five musicians: a singer, flutist, treser,${ }^{8}$ bongo player, and violinist. We explained the project to each of the musicians and asked them if they would be interested in participating in the project. All of them accepted. We asked the musicians to improvise or to compose an original piece that could be potentially put into dialogue with a performance by Eduardo (which would be different from the clip). The instructions were as

8 A tresera refers to a woman who plays a traditional Cuban guitar made of three courses (groups) of two strings. 
follows: play excerpts from your music, take pauses, listen, and react as if Eduardo was sharing the stage with you (see illustration 3). We recorded the audio and video of the five musicians individually performing their own music or improvising at a local theatre called Cabildo, located on Enramada Street, the main shopping street in Santiago de Cuba. Each musician performed eight times to allow us to record various shots of them playing (close ups, side shots, medium shots, long shots, stable shots, moving shots, etc.). We recorded the sound of their performances using a multidirectional microphone placed in front of the stage, and a lapel microphone attached to the musician. In collaboration with a team of local technicians, we carefully reproduced the lighting conditions that we had created at Sala Rossa in Montréal. We also tried to limit any sound contamination from beyond the theatre room, mainly from the busy street. All of these criteria needed to be met in order to reach the sonic and visual characteristics of the relation we planned to create (see illustration 4). We left Santiago de Cuba with all the video rushes and sound digital material on a portable hard drive.

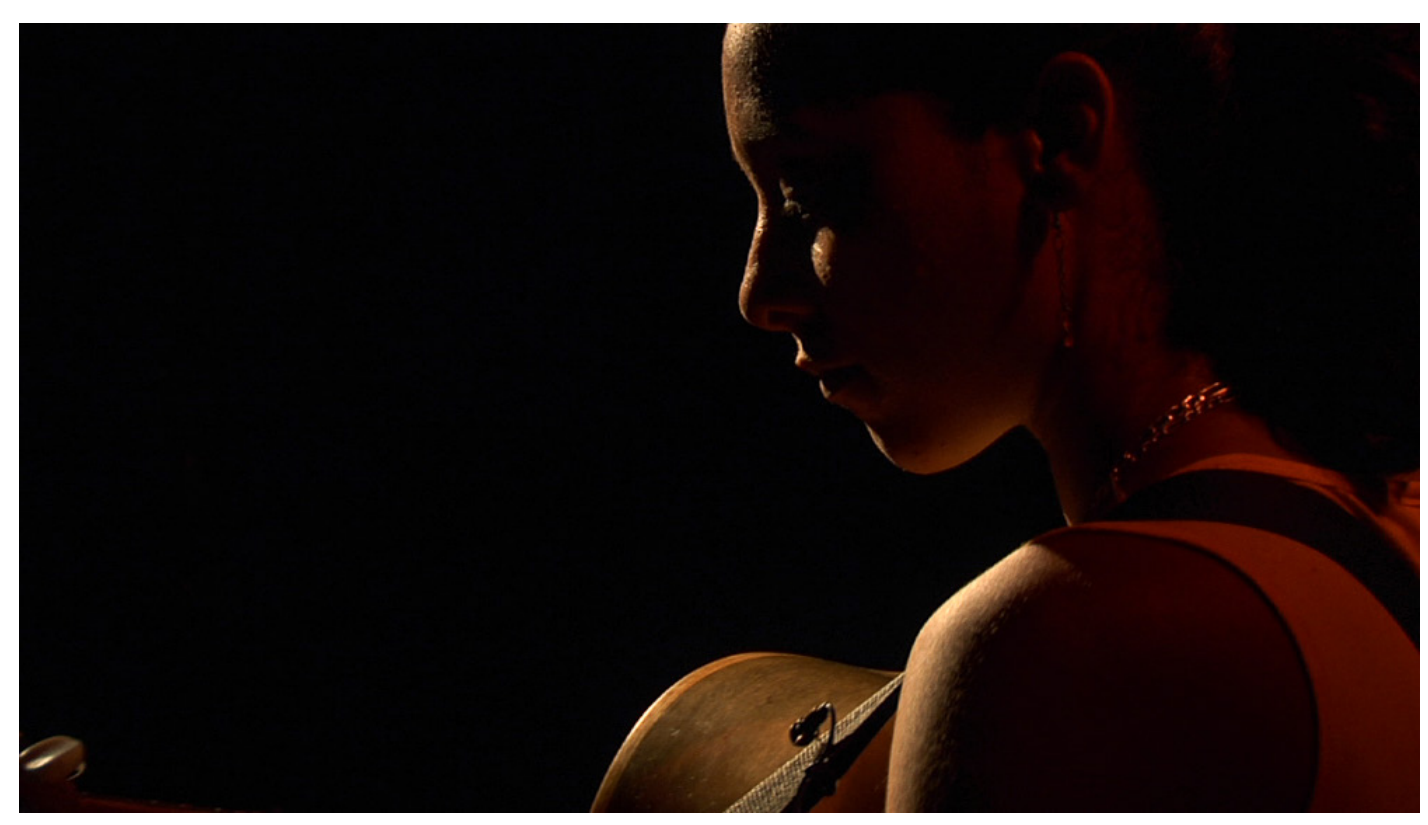

Illustration 3: Yeniset Boudet Sarmiento, tresera in Santiago de Cuba Credit: Marie-Josée Proulx.

The third stage of the project took place in Montréal. During a three-month period, we met with Eduardo on various occasions to show him the collected material. To broaden our scope, we also invited the Cuban pianist Neisy Wilson, who had been living in Montréal for two years, to join us on these occasions. Neisy and Eduardo had known each other since the beginning of 2010, and had shared the stage at various Latin music concerts. Neisy is an excellent pianist who likes composing and improvising. After a two-year tour in Jordan, she was on her way back to Cuba via a connecting flight in Montréal, and decided to stay in Canada. We asked Neisy if she would agree to participate in the project by selecting a musician with whom she would also like to collaborate, and she gladly accepted. Both Neisy and Eduardo are originally from Santiago de Cuba, which made the process quite emotional for them, as they melancholically connected with musicians and music from their hometown (on the diasporic experience of the Echo project, see Boudreault-Fournier 2012).

In order to begin creating the encounters, we asked Eduardo and Neisy to select one musician with whom each of them would like to continue the process. The instructions were: 1) Select one musician among the five participants; and 2) React musically and physically-by 
imagining the other musician's presence-during your performance. We gave Eduardo and Neisy a DVD that included five clips of the five respective musicians from Santiago de Cuba. For one month, they listened to the clips, they watched the musicians' performances, and they prepared their own responses to the musicians they had selected.

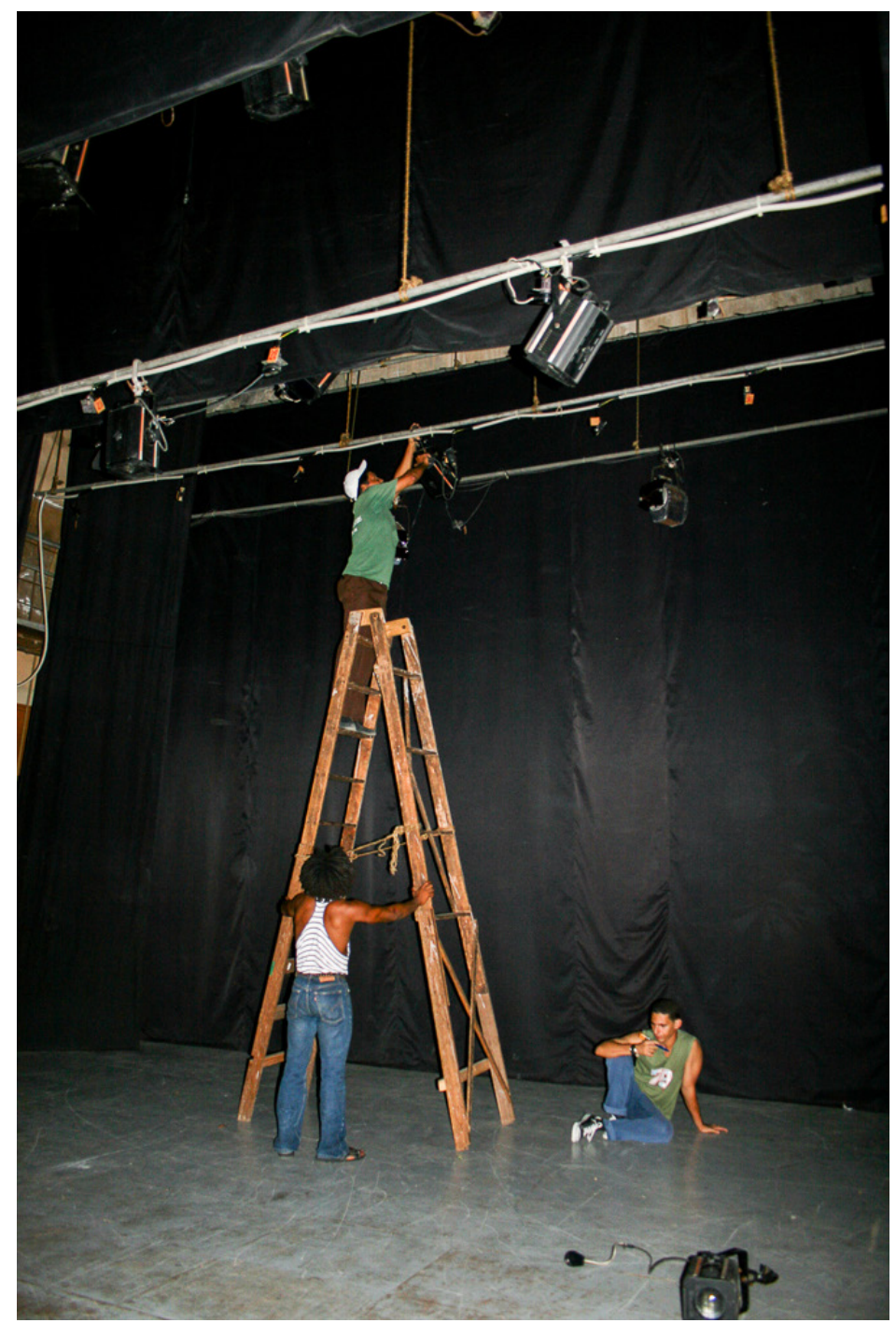

Illustration 4: Technicians in Santiago de Cuba carefully producing the aesthetic desired for the space of encounter. Credit: Alexandrine Boudreault-Fournier.

Eduardo decided to respond to the performance of Yeniset Boudet Sarmiento, a tresera originally from Santiago de Cuba (Illustration 3). The tres is a traditional three-chord guitar (three pairs of strings, with the pairs tuned to each other to create chords) from Santiago de Cuba; it constitutes the instrumental foundation of the traditional groups of Trova music from Santiago de Cuba. Yeniset is a professional tresera who plays with the group, Las Perlas del Son, also based in Santiago de Cuba. This all-female band almost exclusively plays ballads and traditional songs. Two main elements caught Eduardo's attention when he watched Yeniset play. First, the tres is an instrument that is usually played by men (often older men). Eduardo was surprised by the fact that Yeniset was a young woman who excelled at playing this instrument in such an innovative and confident way. For example, Yeniset plays the tres behind her back and with a glass of water. These aspects encouraged Eduardo to select Yeniset and to prepare a 
response to her performance.

Neisy chose to accompany the singer Orielis Mayet Lugo. Neisy told us that she had seen Orielis in the streets of Santiago when she was living there. Even if she had never talked to her, she knew who she was. Orielis is a member of an Evangelical church and is its main choir singer. Neisy, who appreciates the languorous and rough voices of Afro-American blues and gospel singers, liked Orielis'style right away. Because Neisy had previous experience in composing for this kind of vocal performance, she felt perfectly comfortable playing alongside Orielis. In contrast to Eduardo, who decided to improvise, Neisy composed a piano piece to accompany Orielis.

During the recording of the third stage of the project, Eduardo and Neisy faced the challenge of responding to the respective performances of the musicians they had selected. An earbud allowed them to follow the soundtrack of the other musician's performance as they played their own response. At the end of the recordings at the Claude-Champagne theatre room of the Department of Music at the Universite de Montréal, which again, had to follow the same meticulous technical parameters and the same recording processes as the previous sessions, we produced two clips that united the two duets.

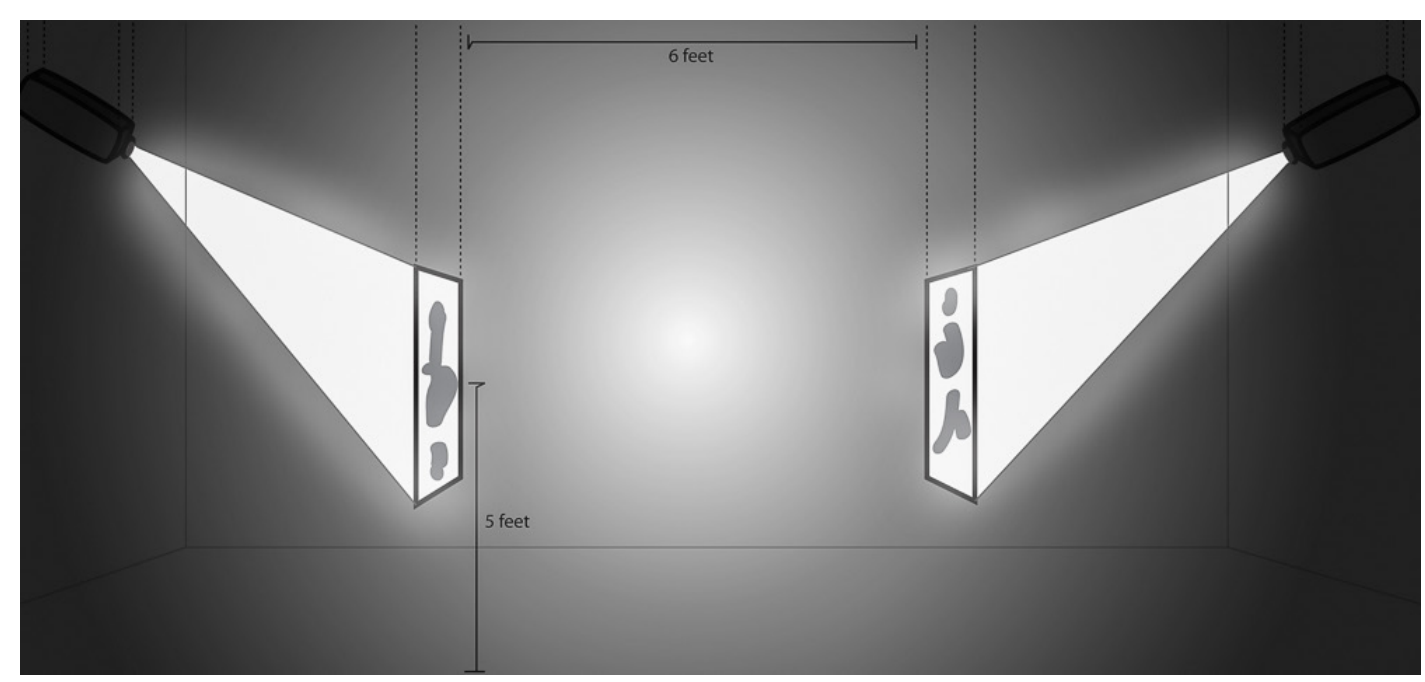

Illustration 5: Ideal setup of the installation "Echo the first tie". Two 42-inch TV screens were used, instead of projectors, for the installation at Ethnographic Terminalia.

The editing of the two clips, more specifically the one uniting Eduardo and Yeniset, was influenced by the selection of the "Echo $\sim$ the first tie" project for the Ethnographic Terminalia collective exhibit that was taking place at Eastern Bloc in Montréal in December 2011. The question of how to present this "zone of correspondence" in an installation format deeply influenced the editing process. For the exhibit, we decided to work exclusively with the Eduardo and Yeniset duet. The exhibition consisted of two 42-inch screens, each showing one of the two musicians (see illustration 5). "Echo the first tie" was installed in a small, dark cubicle, allowing some control over potential sound contamination (other projects were installed nearby). Visitors could walk around the screens, sit down, or simply stand in the middle of the two screens to appreciate the performance. At one point during the installation, Yeniset shifts from one screen to the other. This short passage manipulates the audience's perspective and gives the visual impression more convincingly this time - that Eduardo and Yeniset are physically play- 
ing together, with the soundtrack powerfully adding to the effect. But as we now know, this never happened beyond the digital world. follows:

On the Ethnographic Terminalia website, the "Echo $\sim$ the first tie" project is described as

"Echo the first tie" is a video and sound installation that virtually stages two musicians separated by distance for the time of one original musical piece. More than a technological challenge, it is about inducing a musical dialogue, a relation, which allows a reflection on diasporic nostalgia. [...]

We re-created the same lighting, disposition and mise-en-scène in glacial Montréal and sweltering Cuba with the intention of producing a unique space of dialogue and creation. "Echo $\sim$ the first tie" is the artefact of this encounter. [...]

Studio in unison. The two musicians performed alone. Yet while physically alone, they share the concrete intention of connecting, tying up, with the other, who shares the same motherland, the same language, the same clave. ${ }^{9}$ In "Echo the first tie", their music is one. ${ }^{10}$

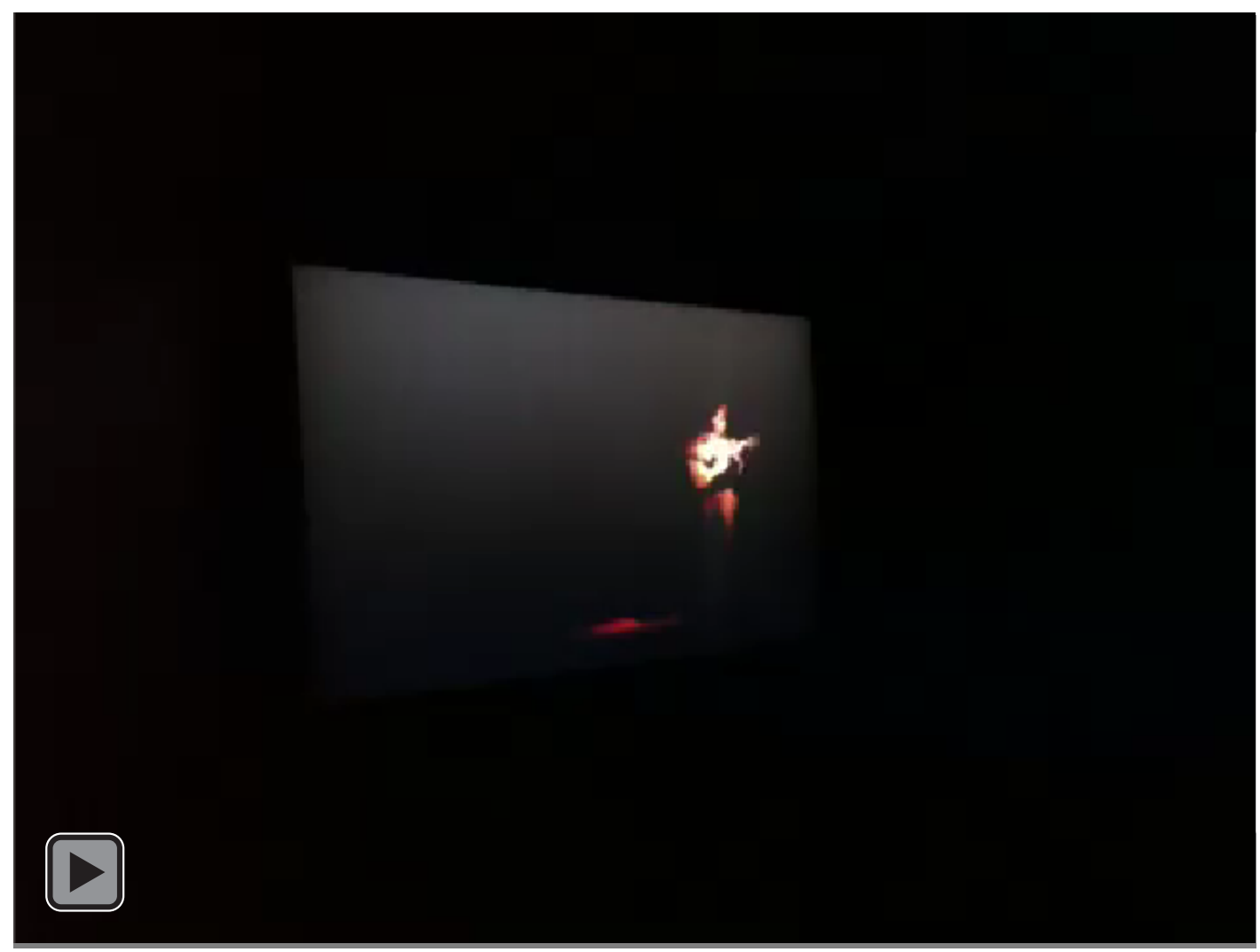

Video 3: "Echo the first tie" (2010) installation at Ethnographic Terminalia 2011. Courtesy of Maryse Morin.

When watching the clip of Eduardo and Yeniset (see video clips 2 and 3), the viewer has to imagine two screens: Yeniset's video on the left screen and Eduardo's video on the right screen. The video clip 2 showing the complete and final editing of Eduardo and Yeniset duet can be seen at this address: https://vimeo.com/153286391. Notice the shift in perspective in video clip 2 when Yeniset moves to the other screen (1'21"). In order to achieve this technical effect,

9 In Cuba, clave refers to an instrument and a rhythm.

10 Full description available here: http://ethnographicterminalia.org/2011-montreal/alexandrine-boudreaultfournier-and-marie-josee-proulx. 
Marie-Josée and I experimented with a few video clips (for instance, video clip 4), trying to create the perfect illusion. The whole process of production was a great technical challenge for both of us, a real technical feat.

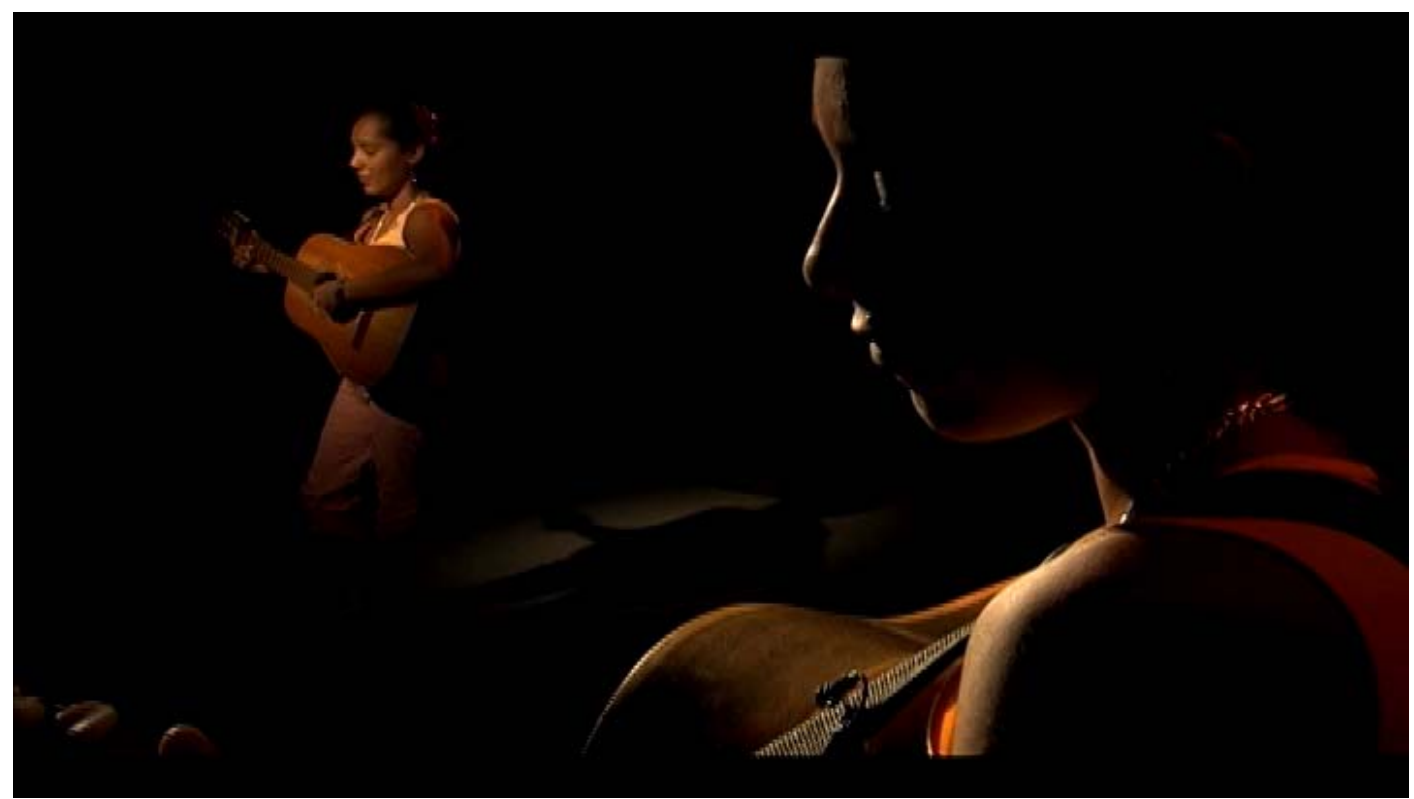

Video 4: Experiments with editing. Credits: Alexandrine Boudreault-Fournier and Marie-Josée Proulx.

The soundtrack uniting Neisy and Orielis is complete, but the visual illusion is imperfect. To experience the final editing of the duet, see video clip 5 at this address: https://vimeo. com/153588720. Apart from experimentations with the video, no installation of this encounter has been produced up to this day. We consider this "zone of correspondence" as part of the Echo project (but not the "Echo the first tie" installation).

The three stages of the project described here are part and parcel of the ethnographic fieldwork during which an anthropologist, in collaboration with a filmmaker, were actively involved in the production of images and sound effects - in addition to staging a virtual encounter. This ethnographic fieldwork was influenced by an artistic approach, which could resemble conceptual art, and could be referred to as Conceptual Ethnography (Ssorin-Chaikov 2013; more below). The field was meticulously set up in accordance with the conventions we had established regarding lighting, the positioning of the musicians, the sonic environment, and the type of recording we captured.

"Echo the first tie" has been publicly exhibited only once, and it was during the Ethnographic Terminalia 2010 edition in Montréal. The musicians never experienced the installation and only viewed a recorded version of the project. Their appreciation of the performance was articulated in terms of "how well they sounded together". ${ }^{11}$ The visitors who went to the gallery could read the exhibit pamphlet with the description of the Echo project cited above. However, many visitors, who had not read the description, were surprised to learn that the musicians had never actually met in person and that we had created a virtual space of en-

11 Eduardo saw the videos the week after the installation. Yeniset, who was in Cuba, saw the videos during the summer of 2011 during Boudreault-Fournier's trip to Santiago de Cuba. 
counter. In retrospect, Marie-Josée and I agreed that the illusion between Eduardo and Yeniset was successful as it convincingly created a sense of coevalness. This illusion was complete despite the fact that the musicians did not share the same screen (except for a few minutes); they were divided visually. It was the soundtrack that glued the whole performance together and provided an audio-visual illusion, which successfully welded two performers into one musical piece.

\section{Relational aesthetics and the Echo Project}

During production of the Echo project, I reflected on my own creative approach, as an anthropologist involved in designing an aesthetic through the recording and editing of images and sounds. I am not only an observer; I assume my role as a creative agent, as a producer-researcher (Boudreault-Fournier 2012; Boudreault-Fournier and Wees forthcoming). The Echo Project was highly influenced by the writings of curators and art critics, as well as works of art that aim at "provoking social relations". A closer look at Bourriaud's work and his concept of "relational art" allow for a deeper appreciation of the perspective I adopted for the Echo project. The art critic defines relational art as a "Group of artistic practices that takes as a theoretical and practical starting point all human relations in their social context, rather than in a private and autonomous space" (Bourriaud 2001:117). ${ }^{12}$ Bourriaud also explains that contemporary artists aim at constructing "artistic practices in correspondence" or forms of art whose substratum is the production of inter-subjective relations (Bourriaud 2001:15). To put it plainly, "the idea of relational aesthetics is that an art form is a form of social exchange" (Martin 2007:370; my translation). It is a call to create beyond the walls of museums and to dig into human relations. It is a shift from the artwork as an object to the artwork as an event (Martel 2008-2009:28). In this context, human relationships become the artistic work (Schneider \& Wright 2010:11), implying that they can be viewed as aesthetic experiences (Kester 2004).

A relational aesthetic also implies the "creation of zones of correspondences", within which links of sharing can be activated (Martel 2008-2009:27). Bourriaud (2001) provides various examples of such "zones of correspondences" or of microtopias, which he defines as "areas of exchanges" and that he considers as exhibiting a relational aesthetic. For instance, "Rirkrit Tiravanija organizes a dinner in a collector's home, and leaves him all the ingredients required to make a Thai soup. [...] Christine Hill works as a check-out assistant in a supermarket, and organizes a weekly gym workshop in a gallery" (Bourriaud 2001:7-8). The creation of zones of correspondence, or a microtopia, is what the Echo project is about. Through the production of video, which includes the anthropologist's recording and editing of images and sounds, I am engaged in designing a space of inter-subjective encounter.

The concept of relational aesthetic is still attracting a modest interest in anthropology, although recent works on the concept significantly contribute to the creation of a thriving field of exchange and conversation (for instance Born 2010; Marrero-Guillamón 2012; BoudreaultFournier 2012; Ssorin-Chaikov 2013; Sansi 2015; Flynn and Tinius 2015). Yet, in compari-

12 I translated all direct quotes from Bourriaud 2001. 
son to anthropology, the concept of relational aesthetics is already a dominant concept at the international level in the domain of visual and media arts (Barber 2008-2009). It is also true that fewer anthropologists have fully exploited the possibilities offered by the video medium, in comparison to visual and media artists who experiment with the dimensions of sound and image production (Schneider 2006; 2008; see also Taylor 1996). Concretely, this appropriation of the visual implies that the anthropologist fully assumes her role in the manipulation of images and sounds. Intervening on sounds and images as a process of investigation-as illustrated by the Echo project - raises many issues in regard to the ethnographic enterprise, as well as to the role of the anthropologist. Indeed, the manipulation of sounds and images may also raise ethical concerns. Yet, the transformation of images and sounds is not associated only with experimental approaches in ethnographic filmmaking. Films that belong to an observational genre-the flyon-the-wall approach - are also constructed through a process of montage, mise-en-scène, and experimentation (Grimshaw, Owen \& Ratz 2010).

When editing, the anthropologist comes to fully understand the various components that are juxtaposed to create a certain meaning. The struggle to create an illusion through montage, which Marie-Josée Proulx and I came to humorously call the rompe cabeza, which means "puzzle" in Spanish but could be translated literally as "head breaking" in English, deeply influenced the whole process as well as the aesthetics of the zone of encounter. Montage can be defined as the process through which audio-visual clips are juxtaposed to produce a storyline (Marcus 1990). This process lies at the heart of a filmic narrative because it establishes associations between clips that might not otherwise have any relationship to one another. More specifically, montage refers to the "joining together of different elements in a variety of combinations, repetitions, and overlaps" (Willerslev \& Suhr 2013:1). The process of montage implied doing, making and experimenting with the data we collected during what we considered to be ethnographic fieldwork. In this sense, "montage suggests experiments in the constitution of the data of ethnography - that is, with the engagement and constitution of the material itself" (Marcus 2013: 304).

Even if the montage of the video and audio was equally important to create the virtual encounter, we did not edit the sound as much as the video. The soundtrack that emerged from the musicians' performances remains almost intact in comparison with the images that were chopped and altered. In the editing suite, the soundtrack became the base from which we worked upon the visual elements. This is indicative of how the virtual encounter was underpinned by the musical performance.

Accordingly, the process of production and post-production (in the editing suite) provided avenues for exploring alternative conceptions of the fieldwork enterprise. In concrete terms and in the case of the Echo project, investigating the potential of a relational aesthetics within our approach implied that we considered the encounter between anthropologists and all the involved actors (musicians, technicians, collaborators, local coordinators, etc.) as part of the experience. It also implied that we look at the project's "constructed conviviality" (Bourriaud 2001), through image and sound montage, as experiences that generate forms of anthropological knowledge. Thera Mjaaland (2009) adopts a similar approach in suggesting that anthropological knowledge emerges through the meeting of, and the relation between, the photographer and the person in front of the camera (which can be the anthropologist in both cases). In the case of the Echo project, the editing of video and sound clips constituted an additional key aspect of the fieldwork enterprise. By intervening in the production of a space of relations and 
of virtual creation, we positioned ourselves within a series of relations that stem from shared experiences. It was through the process of developing relations with the musicians and the people involved in the project, as well as building a virtual space of encounter-a microtopia - that our fieldwork took shape.

The "Echo the first tie" exhibition at Ethnographic Terminalia in 2011 became the record of such a process. It is through the exhibition of the piece that a shared musical experience may be lived and felt with the audience. Yet, the final audio-visual product that unites the two musicians is less significant than the reflections that have emerged-and that are still emerging-from the process of producing and editing the video and its accompanying soundtrack. Additionally, the construction of meaning by anthropologists and the transformation of meaning by a participatory audience should also be considered as a significant aspect of our role as actors engaged in a multitude of social relations. Relational art, according to Bourriaud (2001), should generate other relations, which should in turn exponentially generate yet others.

From the Echo project's conception to its exhibition at Ethnographic Terminalia, the integration of elements that are traditionally considered exogenous to our discipline transformed my role as an anthropologist. More than a participant observer, I became an anthropologist with creative agency. I also became a "matchmaker" or "go-between". In other words, I completely mapped out the space of encounter. There is, in this case, a transposition of the anthropologist as a participant observer to a "role of social agent" (Mjaaland 2009). This taking of action [prise d'action] and intervention in the field is not new to our discipline. Projects led by anthropologists and defined as "Indigenous media" are examples of such forms of intervention (the Kayapo video project and the Navajo film project are the most common examples). The anthropologist's involvement in creating spaces where participants express themselves is a common strategy of data collection in anthropology. In encouraging the artist Tshibumba Kanda Matalu to paint the history of Zaire and to comment on a series of artworks in the process of being created, Johannes Fabian (1996) provides a complex and fascinating portrayal of memory and of the postcolonial experience. Discussion groups are another example of a common research method used to contribute to the mise-en-scène of a space of encounter that would not have emerged spontaneously. In large part, it is the anthropologist who creates these spaces.

What is innovative in the Echo project is its use of technological practices and montage techniques that are based on a serious consideration of contemporary arts and their creation processes as avenues of methodological exploration during the fieldwork enterprise. This methodological approach implies a new reconfiguration of the ethnographic fieldwork experience. Fieldwork becomes a space of exploration and creation. According to this approach, it is not only the performance and the agency of the objects or the participants of a study that are the main focus of the anthropologist's "gaze", but also and most importantly, it is the anthropologist's own visual and sonic practices in producing the relational encounter that become the focus of attention.

\section{BUILDING ON CRITICISMS: THE RELATION}

In taking the role of the anthropologist as the "cartographer of encounters", I recognize that there is a danger of creating "artificial" relations, as suggested by some criticisms of the 
Echo project. Are the musicians "playing along" in order to satisfy the desire of the stage director (i.e. the anthropologist)? Are the musicians really engaging with the Other or are they only superficially involved? These are complex questions, which certainly need to be addressed. However, they do not constitute new concerns for our discipline. The anthropologist-informant relationship has often been described as problematic, if not destabilizing (for instance Fieldwork in Morocco by Rabinow 1977) rather than fully genuine and "non-artificial". Indeed, the Echo Project raises many of these concerns, one of them being the nature of the relationships between the anthropologist and the informant as well as between the participants who are involved in the inter-subjective relation.

Claire Bishop provides one of the most insightful criticisms of Nicolas Bourriaud's work. Other criticisms such as those of Grant Kester (in Conversation Pieces 2004), Stewart Martin (in Third Text in 2007) and Julian Stallabrass (in Art Incorporated 2004) also highlight similar concerns, which are closely related to the criticisms I raised above in regard to the Echo Project.

More precisely, in her article "Antagonism and Relational Aesthetics”, Claire Bishop argues that Bourriaud does not provide any insights for judging and measuring the quality of the relationships generated by relational aesthetics pieces. She correctly notes that for Bourriaud, it seems that any type of relation that permits dialogue "is automatically assumed to be democratic and therefore good" (Bishop 2004:65). She further asks: "what types of relations are being produced, for whom and why?" (Ibid.). Briefly, Bishop argues that it is not enough "to say that activating the viewer tout court is a democratic act" (Ibid.:78). Rather than looking at harmonious relationships in micro-spaces, we should think about an aesthetic of antagonism as providing "concrete and polemical grounds for rethinking our relationship to the world and to one other" (Ibid.:79). She provides examples of artists who develop an aesthetic of antagonism. These include Santiago Sierra with his works " $250 \mathrm{~cm}$ Line Tatooed on Six Paid People”, exhibited in Havana in 1999, and "Workers Who Cannot be Paid, Remunerated to Remain Inside Cardboard Boxes" exhibited in Berlin in 2000. These micro-spaces are politically provocative, indeed, but they would never receive the approbation of any Human Research Ethics Board that anthropologists need to respond to. Provoking antagonism in a micro-space, from an anthropological perspective, would certainly generate serious ethical problems. For this reason, Bourriaud's conception of microtopia (see more below), despite Bishop's critique, might better correspond to the ethical principles associated with the discipline of anthropology.

Georgina Born (2010) reflects on some of these issues in building upon the criticism of relational aesthetics. Born argues for a more complex, if not agonistic and on occasion antagonistic, approach to the relation in anthropology. She highlights how social relations in the field, like conceptual art, are double-ordered, playing on both the real and artificial sides of the relation between anthropologists and their informants in the field.

In relation to the Echo project, the main point to be highlighted from the critique developed by Bishop and others is that relational aesthetics, as defined by Bourriaud, implies the production of spaces of encounter that do not critically look at social relationships in today's society. Some more radical artistic collectives, such as the Radical Culture Research Collective, also argue that forms of art that would fit within this model of relational aesthetics do not pro- 
pose radical changes to the ways in which our society is organized. ${ }^{13}$ In other words, the nature of the relation, as proposed by Bourriaud, does not call for democratic dialogue; it cannot be understood as representing a process in which conflicts, injustices and political issues are addressed (among others).

If we apply this reflection to my methodological approach, I might question the agency of the participants/musicians as expressed throughout the process of producing the Echo project and as influencing the installation that was publicly presented. Did I provide a space that fostered genuine dialogue? Can I escape from the political? And did I avoid the political? The Echo project is relational, but what type of relationship did we provoke through the video medium? These questions can also be transposed into a broader approach to the relation in anthropology.

The Echo project has not been designed to address a political issue in the way Bishop understands it. The relation as defined by Bourriaud may not be political in the sense that Bishop would like it to be. Yet, it encourages a discussion of how micro-utopian spaces can become "political" in contributing to the construction of alternative and parallel spaces in which the mundane and the everyday life are disrupted and transformed, and in which new reflections can emerge. Bourriaud (2001) argues that all spaces of exchange created by artists are political because they are constructed as interstitial spaces that provide a different temporal and spatial context than the most common "communication zones" in which humans are entangled. Bourriaud writes that "contemporary art develops a political project when it strives to invest the relational sphere by problematizing it" (2001:17). The political is understood as a space of dialogue, experimentation and reflection; it directs us towards another interpretation than that which is proposed by Bishop.

Relational spaces created by artists, but not limited to them (see Sansi's 2015 discussion of activists creating micro-utopias), can become political in the sense that micro-utopian spaces can generate novel ways of thinking together about the world in which we live. This corresponds to a "relational reflexivity", a term coined by Flynn and Tinius (2015:7) to refer to "performances that problematise negotiation and process, rather than propagate fixity and identity" (their emphasis). In a very modest way, the design, production and post-production of the Echo project aimed at creating a space of exploration in which further questions about my role as an ethnographer, or a metteur-en-scène (see next section), and also about ethnographic fieldwork in general could be raised. Some of those questions emerged unexpectedly and many aspects of the project were unknown to me until the very end, such as the reception of the piece by an audience. The process of creating the Echo project did not provide final answers to all my questions. Yet, I believe that reflecting on the creative process (i.e. the fieldwork enterprise) is more revealing than focusing on the definitive outcomes (i.e. publications).

The process of creation corresponded to an improvised work, a process of carrying on (Ingold 2013), in which altering the material meant an ongoing period of reflection with its associated transformative effects. Carrying on is a "passage along a path in which every step grows from the one before and into the one following, on an itinerary that overshoots its destination" (Ingold 2013:45). Ingold (2013) makes a distinction between ethnography and anthropology; ethnography serves as a documentary purpose while anthropology acts in a transformative way.

13 "A Very Short Critique of Relational Aesthetics". Radical Culture Research Collective, see http://transform. eipcp.net/correspondence/1196340894\#redir 
In this sense, carrying on is anthropology, and one could argue, carrying on is also art.

How art and its processes of creation can lead anthropologists to reconfigure our own ethnographic enterprise is a question that lies at the heart of the Echo project. Nikolai SsorinChaikov (2013) proposes a methodology that positions art and anthropology symmetrically and which highlights various intentions behind the Echo project. Ethnographic conceptualism, explains Ssorin-Chaikov "is ethnography conducted as conceptual art" (2013:6), and "it uses art to generate ethnographic situations" (2013:8). He further explains that Conceptual Ethnography "reveals social and aesthetic potentialities. It elicits new responses and reactions, explicates unexpected links, points out unforeseen aesthetics figurations" (2013:15). Conceptual Ethnography constructs a reality that is unknown and it creates "anti-facts" that are not objects and tangible materialities but perform "new results" (2013:16).

I do not claim that the Echo project is a form of conceptual art, and even less that I am an artist. However, the process of creating a microtopia, a virtual space of encounter, that was constructed until the end using various technological tools, follows in many ways what Conceptual Ethnography, as I understand it, could look like. The Echo project is not about analyzing conceptual art per se, but similarly to the artist who is the instigator of the relation, it is about designing and creating spaces through which, the anthropologist stages and reflects on the scene of the encounter.

\section{ON MISE-EN-SCÈnE}

This mise-en-scène of a human coexistence is an aesthetic call for critically rethinking our approach in anthropology. In this sense, Echo can be approached as a project that attempts to push the boundaries and to experiment with new horizons and perspectives, with the aim of better conceiving the ethnographic enterprise. Chantal Mouffe's discussion of the relationship between art and politics makes it possible to slightly shift the angle of reflection from the political criticism articulated by Bishop and others, which is, I believe, a more fertile perspective when looking at the Echo project. Mouffe (2007:4) argues that:

The political, $[\ldots]$ concerns the symbolic ordering of social relations, what Claude Lefort calls 'the mise en scène', 'the mise en forme' of human coexistence and this is where lies its aesthetic dimension. (Ibid.; her emphasis)

In many ways, anthropologists often control the fieldwork setting, and if we consider the anthropologist as a type of director, a metteur-en-scène, we open the fieldwork enterprise to a series of challenging theoretical questions and methodological re-modelling, also touched upon by the Echo project. Similarly, Richard Freeman (2001) approaches public spaces of Buenos Aires in terms of mise-en-scène. He explains that although mise-en-scène means "staging in action", it does not refer only to "staging", that is, it means more than mere background. He writes: "In theatre and film, the director has complete control over setting. Despite a lack of control in real life, we can see players in society attempt to do precisely what film and theatre directors do-control the set" (38). The anthropologists and the participants are engaged in the staging of the "zones of correspondence". 
Similarly, Perle Møhl (2011:227) argues that approaching fieldwork as a "filming anthropologist" "creates a cooperative frame, a stage, for the production of new insights and knowledge", a site where participants act and behave in certain ways in front of and away from the camera-a Goffmanesque approach to fieldwork-providing evidence that participants are agents in their own representations. Approaching the Echo project as the product of a miseen-scène through the participation of both the anthropologist and the participants requires us to think in terms of relation and aesthetic-how we can define the relation in terms of an aesthetic of encounter-as it forces us to imagine the anthropologist as a creative agent, rather than only a participant observer.

\section{Conclusion}

The intention of creating a convincing virtual space of encounter based on the manipulation of images and sounds through digital technologies was a leading motivation throughout the production of the Echo project. Why? Simply put, Marie-Josée Proulx and I wanted "to make the relation work". We wanted to create a successful prototype, a microtopia of a relation that looked as if it was based on a physical co-presence, a mutual connection and communication. We felt the virtual effect did not fully work with the Neisy and Orielis duet, mainly because of the visual dimension. Yet, the unspoken relation between Eduardo and Yeniset convinced us. But what does that say about the aesthetic of the relation that we created in the Echo project?

In order to sketch an answer to these questions, I would like to interweave two main ideas. The first one is the concept of counterpoint, as mentioned above, but with a particular emphasis on the musical version of the term's definition. Counterpoint is about a sonic interweaving, which creates a sense of togetherness. "Togetherness" corresponds to the second idea I will discuss further. In his oft cited article, Alfred Schütz (1951) develops the idea of togetherness, the sense of a "We", and the vivid presence involved in the act of playing music. His work is particularly revealing to engage with the Echo project's relational aesthetic. He argues that all social communication is based on the idea of "mutual tuning-in relationship", an inclusive connection between different actors involved in a shared place and time. The "tuning-in relationship" has an implicit temporal dimension, Schütz argues, as it implies "growing together while the musical process lasts" (1951:93) and "living simultaneously in several dimensions of time" (1951:94). The actual playing of a written piece of music by a performer is influenced by a web of historical and autobiographical factors such as how the performer learned to play, who were the masters who influenced him, and who were the masters who influenced his masters. The "bulk of musical knowledge - as of knowledge in general - is socially derived" and socially approved (1951:86), which implies that it is based on a web of musical and metamusical factors (1951:81). In other words, biographical and historical journeys of the social - not directly relevant to the musical - have an impact on how music is performed and experienced.

The Echo project reflects Schütz's historical vision of "togetherness". The Echo project is about two musicians from Santiago de Cuba, who live apart and meet in a virtual space. Eduardo had not been able to go back to Cuba until recently and his life has been strongly tied to the memory of his motherland. Eduardo's and Yeniset's improvisations were imbued by their respective trajectories. Yeniset playing the tres with a glass of water is certainly tied to her performing in a non-traditional way for a woman. A web of biographical and social factors 
influenced their performances. Yet, the Echo project also questions the necessary physical copresence of "togetherness" in the musical performance as described by Schütz. The editing of the two soundtracks together meant that the two webs were connected into a digitally shared experience, a virtual performance, but a successful counterpoint. The Eduardo and Yeniset relation is therefore based on a sonic, more specifically musical, shared space of encounter, an encounter that even the anthropologist-metteur-en-scène was not in control of. I believe that this encounter could fully take place through a sonic aesthetic based on the musical improvisation of the two participants. In many ways, this is how Eduardo and Yeniset created their relation, not only between them but also between Marie-Josée and me. However, what is interwoven in the Echo project, is much more than two musicians playing together. It is a shared moment based on musical and metamusical experiences that correspond (Ingold 2013) or come together through the digital manipulation of recordings. But like the ajiaco that cooks slowly, my hope is that relational aesthetic, as explored in the Echo project, continues to be a key ingredient of future anthropological endeavours.

\section{References}

Barber, Bruce. 2008-2009. "Sur la mort [du social] dans la pratique de l'art relationnel." Inter: Art Actuel 101:40-47.

Bishop, Claire. 2004. "Antagonism and Relational Aesthetics.” OCTOBER 110 Fall 51-79.

Born, Georgina. 2010. "After Relational Aesthetics: Improvised Musics, the Social, and (Re) Theorising the Aesthetic." Unpublished paper presented at the "Improvisation and Social Aesthetics Conference", McGill University, Montréal.

Boudreault-Fournier, Alexandrine. 2012. "Écho d'une rencontre virtuelle: Vers une ethnographie de la production audio-visuelle." Anthropologica 54:7-18.

Boudreault-Fournier, Alexandrine and Nick Wees. Forthcoming. "Creative Engagement with Interstitial Urban Spaces: The Case of the Vancouver's Back Alleys." in Urban Encounters: Art and the Public, edited by Martha Radice and Alexandrine Boudreault-Fournier. McGill University Press: Culture of Cities Series.

Bourriaud, Nicolas. 2001. Esthétique relationelle. Les presses du réel.

Fabian, Johannes. 1996. Remembering the Present: Painting and Popular History in Zaire. Berkeley: University of California Press.

Flynn, Alex and Jonas Tinius. 2015. "Reflecting on Political Performance: Introducing Critical Perspectives." Pp. 1-28 in Anthropology, Theatre, and Development: The Transformative Potential of Performance, edited by Alex Flynn and Jonas Tinius. New York: Palgrave MacMillan.

Freeman, Richard. 2001. "The City as Mise-en-Scène: A Visual Exploration of the Culture of Politics in Buenos Aires." Visual Anthropology Review 17(1):36-59.

Grimshaw, Anna, Elpseth Owen and Amanda Ravetz. 2010. "Making Do: The Materials of Art and Anthropology." Pp. 147-162 in Between Art and Anthropology: Contemporary Ethnographic Practice, edited by Arnd Schneider and Christophe Wright. Oxford: Berg.

Ingold, Tim. 2013. Making: Anthropology, Archaeology, Art and Architecture. London: Routledge.

Kester, Grant H. 2004. Conversation Pieces: Community + Communication in Modern Art. Berkeley: University of California Press.

Marcus, George E. 1990. "The Modernist Sensibility in Recent Ethnographic Writing and the Cinematic Metaphor of Montage.” Visual Anthropology Review 6(1):2-12. 
. 2013. "The Traffic in Montage, Then and Now." Pp. 1-15 in Transcultural Montage, edited by Christian Suhr and Rane Willerslev. New York: Berghahn.

Marrero-Guillamón, Isaac. 2012. "Together apart: Hackney Wick, The Olympic Site And Relational Art." Architecture Research Quarterly 18(4):367-376.

Martel, Richard. 2008-2009. "Récurrence et historicisme: la relation." Inter: Art Actuel 101:2629.

Martin, Stewart. 2007. “Critique of Relational Aesthetics.” Third Text 21(4):369-386.

Mjaaland, Thera. 2009. "Evocative Encounters: An Exploration of Artistic Practice as a Visual Research Method.” Visual Anthropology 22(5):393-411.

Møhl, Perle. 2011. "Mise en scène, Knowledge and Participation: Considerations of a Filming Anthropologist." Visual Anthropology 24(3):227-245.

Mouffe, Chantal. 2007. "Artistic Activism and Agonistic Spaces." Art Eซ Research: A Journal of Ideas, Contexts and Methods 1(2):1-5.

Ortiz, Fernando. 1983. Contrapunteo cubano, del Tabaco y el azúcar. La Habana: Editorial de Ciencias Sociales.

.2014. “The Human Factors of Cubanidad.” Journal of Ethnographic Theory 4(3). (http:// www.haujournal.org/index.php/hau/article/view/hau4.3.031/1723).

Palmié, Stephan. 2013. The Cooking of History: How Not To Study Afro-Cuban Religion. Chicago: The University of Chicago Press.

Rabinow, Paul. 1977. Reflections on Fieldwork in Morocco. Berkeley: University of California Press.

Sansi, Roger. 2015. Art, Anthropology and the Gift. London: Bloomsbury Publishing.

Schneider, Arnd. 2006. Appropriation as Practice: Art and Identity in Argentina. London: Palgrave Macmillan.

2008. "Three Modes of Experimentation With Art and Ethnography." Journal of the Royal Antbropological Institute 14:171-194.

Schneider, Arnd \& Christopher Wright. 2010. "Between Art and Anthropology.” Pp. 11 in Between Art and Anthropology: Contemporary Ethnographic Practice. Arnd Schneider and Christophe Wright. Oxford: Berg.

Schütz, Alfred. 1951. "Making Music Together: A Study in Social Relationship." Social Research 18(1):76-97.

Ssorin-Chaikov, Nikolai. 2013. "Ethnographic Conceptualism: An Introduction.” Laboratorium 5(2):5-18.

Stallabrass, Julian. 2004. Art incorporated: The Story of Contemporary Art. Oxford: Oxford University Press.

Tanaka,Atau.2006."Interaction, Experience and the Future of Music."Pp.211-239 in Consuming Music Together. Social and Collaborative Aspects of Music Consumption Technologies, edited by Kenton O'Hara and Barry Brown. Dordrecht: Springer.

Taylor, Lucien. 1996. "Iconophobia." Transition 1996 69:64-88.

Willerslev, Rane \& Christian Suhr. 2013. "Montage as an Amplifier of Invisibility." Pp. 1-15 in Transcultural Montage, edited by Christian Suhr and Rane Willerslev. New York: Berghahn. 